\title{
Avaliação qualitativa e quantitativa da arborização das praças de Vinhedo, SP
}

\author{
ROBERVAL DE CÁSSIA SALVADOR RIBEIRO (1); ISABEL CRISTINA FIALHO HARDER (2) e ARMANDO REIS TAVARES (3)
}

\begin{abstract}
RESUMO
O inventário das espécies arbóreas e dos respectivos números de indivíduos das praças da cidade de Vinhedo foi realizado no perímetro urbano, excetuando-se os condomínios, as áreas de parques e as de preservação de mananciais. Para a localização das áreas, consultou-se a planta do município de 1997. Realizou-se o inventário da vegetação arbórea, considerando-se apenas os indivíduos com CAP (circunferência à altura do peito) acima de $10 \mathrm{~cm}$ listando-se as seguintes informações: nomes comum e científico das espécies; CAP; altura; aspecto geral; diâmetro de copa; presença de pragas, doenças ou parasitas; ocorrência de podas (drástica e/ou de condução); fitossanidade da raiz, tronco e copa. Foram registradas 22 praças por nome, localização e número total de árvores, totalizando 764 indivíduos pertencentes a 23 famílias botânicas e 53 espécies, além de 32 indivíduos não identificados. A espécie de maior abundância relativa foi Syagrus romanzoffiana (jerivá), com 31,94\% do número total de indivíduos. Em 63,64\% das praças 33,13\% das espécies eram exóticas. A maior parte dos indivíduos tinha aspecto geral normal, demonstrando prática de tratos culturais adequados. Na maioria dos casos, as podas foram feitas corretamente, ou não houve a necessidade de nenhuma intervenção. Do total de 22 praças, apenas cinco tinham bom estado geral de conservação dos elementos naturais (arbustos, canteiros e gramados). Em 68,18\% das praças as árvores tinham altura superior a 6 metros, indicando que essas áreas necessitavam apenas de procedimentos de manutenção de rotina. E 22,72\% necessitavam de práticas de manutenção mais direcionadas ao desenvolvimento das árvores, tais como adubações periódicas, capinas, podas de condução e, finalmente, em $13,64 \%$ deveriam ocorrer intervenções tanto de manutenção, como de recuperação por meio de novos plantios, ou mesmo, de planejamento para remodelação da área.
\end{abstract}

Palavras-chave: arborização urbana, inventário, praças.

\section{ABSTRACT}

Qualitative and quantitative tree evaluation of areas in Vinhedo, SP, Brazil.

An inventory of the tree species in the squares of the city of Vinhedo was accomplished in the urban perimeter, except for condominiums, parks and springs preservation areas. To locate the areas to be inventoried, a 1977 city map was used. Specimens with circumference breast height,(CAP) above $10 \mathrm{~cm}$ were considered for the inventory, which included the following parameters: common and scientific names of each species; CAP; height; general appearance, canopy diameter; presence of diseases or insects; occurrence of pruning (drastic and/or corrective); root, trunk and crown health. The data registered for the 22 squares were: square identification, location and the number of trees, resulting in 764 individuals belonging to 23 botanical families and 53 species, not including 32 unidentified specimens. The highest relative species abundance was Syagrus romanzoffiana (Cham.) Glassm. (jerivá), with $31.94 \%$ of the individuals. In $63.64 \%$ of the squares, less than 50\% were exotics. Most of the specimens had normal appearance.. In most cases where pruning had been done, it was done correctly. From all 22 squares, only five represented good general states of conservation of the specimens. In $68.18 \%$ of the squares, the trees were taller than $6 \mathrm{~m}$, representing areas that needed only routine maintenance procedures, while $22.72 \%$ needed periodic maintenance practices such as amending soil, weeding, and pruning. Finally, in $13.64 \%$ of the squares needed new landscape design and installation.

Key words: Urban forestry, inventory, city squares.

\section{INTRODUÇÃO}

A arborização urbana caracteriza-se como um dos mais importantes elementos que compõem o ecossistema das cidades e que, pelos benefícios que produz, deveria ser uma preocupação permanente de todo e qualquer planejamento urbano (VERAS, 1986).

A ocupação dos espaços na malha urbana, de forma desordenada, nem sempre propicia a reserva de áreas destinadas à implantação de praças e parques. Não existe a correspondente relação entre a necessidade do homem moderno de espaços para fins recreativos e de lazer e sua disponibilidade (SANTOS \& TEIXEIRA, 2001).

A escolha das espécies vegetais deve estar apoiada em critérios técnico-científicos, que envolvem a análise das condições ambientais locais e as características fisiológicas e morfológicas das árvores. Para alcançar o desenvolvimento satisfatório e o estado sadio das árvores,

\footnotetext{
(1) Escola Superior de Agricultura “Luiz de Queiroz”, Universidade de São Paulo, Av. Pádua Dias, 11, Caixa Postal 9, 13418-900, Piracicaba (SP) - Brasil.

(2) Instituto Agronômico de Campinas, Estação Experimental Jundiaí - Louveira (CAPTA Frutas Jundiaí) - IAC, Av. Luiz Pereira dos Santos, 1500

- Corrupira - 13.214-820 - Jundiaí (SP) - Brasil. Fone/Fax: (11) 4582-7284 - email: isabo@uol.com.br

(3) Instituto de Botânica, Seção de Ornamentais, Av. Miguel Stéfano, 3687, 04301-012, São Paulo (SP) - Brasil.
} 
é necessário também o planejamento prévio de práticas de manutenção, entre as quais monitoramento, irrigação, adubação, poda e controle fitossanitário são fundamentais (MILANO et al., 1992b).

O plantio de espécies de árvores nativas em ruas, avenidas, parques e praças públicas de nossas cidades é uma prática insignificante, a despeito da riqueza de nossa flora. Isso ocorre exclusivamente por desconhecimento de nossas espécies. Estima-se que aproximadamente 80\% das árvores cultivadas nas ruas das cidades brasileiras são da flora exótica. Evidentemente, nem todas as espécies de árvores da nossa flora prestam-se adequadamente para o plantio em áreas urbanas. A grande maioria, entretanto, pode ser plantada em praças, parques e grandes avenidas (LORENZI, 1998).

Sob essas considerações, o objetivo do presente trabalho consistiu em avaliar quantitativa e qualitativamente a arborização das praças do município de Vinhedo (SP), utilizando procedimentos metodológicos para facilitar a identificação e análise .

\section{MATERIALEMÉTODOS}

\subsection{Descrição da área de estudo}

O município de Vinhedo localiza-se a $23^{\circ} 01^{\prime} 46^{\prime \prime}$ de latitude sul e $46^{\circ} 58^{\prime} 30^{\prime \prime}$ de longitude oeste, tem área de $82 \mathrm{~km}^{2}$ e está situado na região sudeste do Estado de São Paulo, a 76 km da capital. Sua topografia é de conformação suave, rebaixada, com altitudes variando de 700 a 900 metros. O clima, segundo a classificação de Köppen, é Cwa, ou seja, clima subtropical com duas estações definidas, úmida e quente. Regime pluvial marcado por chuvas de verão e inverno seco. A temperatura máxima média do mês mais quente no verão é de $28^{\circ} \mathrm{C}$, e durante o inverno, no mês mais frio, a temperatura média é inferior a $19^{\circ} \mathrm{C}$. Sua pluviosidade média anual é de $1.404 \mathrm{~mm}$ (VINHEDO, 2000).

Os solos da região do município de Vinhedo são do tipo LVA22, ou seja, latossolo vermelho-amarelo, com boa drenagem interna, distrófico, com textura argilosa, além de cambissolos háplicos e distróficos com textura média e argilosa, sendo ambos com horizonte A moderado e proeminente (OLIVEIRA et al., 1999).

A vegetação nativa da região é composta basicamente por cerrado, cerradão e capoeira. O cerrado é conceituado como vegetação xeromorfa, preferencialmente de clima estacional (mais ou menos seis meses secos), podendo ser encontrada também em clima ombrófilo. $\mathrm{O}$ cerradão pertence a um subgrupo do cerrado e tem formação típica e característica, restrita a áreas areníticas lixiviadas com solos profundos, ocorrendo em clima tropical eminentemente estacional, e a capoeira é um estádio sucessional que pode ser detectado por sensoriamento remoto em escala de 1:100.000 (VELOSO et al., 1991).

De acordo com o último censo do IBGE de 2000 (Instituto Brasileiro de Geografia e Estatística, 2002), o município de Vinhedo tem população de 47.215 habitantes. Destes, 46.174 residem na área urbana e 1.041 na área rural. Possui também uma população flutuante de aproximadamente 15.000 habitantes. Sua densidade demográfica é de 522 habitantes por km² .

Os espaços livres existentes e sua distribuição física, no município, foram catalogados como praças, de acordo com sua qualidade de uso, podendo ser bons, regulares, ruins e sem qualidade de uso, porém com potencial, segundo revisão bibliográfica em literatura específica e da coleta de dados. As áreas foram separadas dentro dos bairros encontrados, considerando-se somente o perímetro urbano. Utilizou-se o Sistema Global de Posicionamento (Global Positioning System - GPS), para se obter a localização mais precisa de cada exemplar arbóreo.

Os levantamentos foram realizados no perímetro urbano da cidade de Vinhedo, excetuando-se os condomínios, as áreas de parques (Parque da Uva, Represa e Cristo) e as de preservação de mananciais. Os dados foram coletados durante os meses de abril e maio de 2002 concomitantemente de praças e árvores, de bairro a bairro. Foram utilizados dois tipos de formulários: um para a caracterização das praças e outro para caracterização dos indivíduos arbóreos.

Para a localização das áreas, consultou-se a planta do município de 1997. Nesse mapa, algumas praças aparecem identificadas e demarcadas, porém existem outras áreas que não estão identificadas como praças, mas estão demarcadas. As áreas isentas de identificação foram vistoriadas, sendo excluídas as encostas, parques e áreas de preservação de manancial. Após consulta aos moradores dos bairros, foram localizados alguns espaços que não estavam demarcados no mapa, mas que são utilizados pela população local.

Os bairros foram codificados com a letra B e as praças, com as letras B e P, em que B é o bairro onde se localiza a praça e P, a área inventariada. Essa codificação pode ser observada na tabela 1 .

\subsection{Inventário da arborização das praças}

No inventário da vegetação arbórea, consideraram-se apenas os indivíduos com CAP acima de $10 \mathrm{~cm}$, utilizando-se fita métrica, onde em que plantas com CAP inferior àquele valor tamanho não foram consideradas.

Foram coletados os seguintes dados: CAP; altura; aspecto geral; diâmetro de copa nos sentidos norte/sul e leste/oeste; presença de pragas, doenças ou parasitas; ocorrência de podas (drástica e/ou de condução); fitossanidade da raiz, tronco e copa e necessidade de intervenção.

Para a identificação das espécies comparou-se o material botânico coletado, com a literatura específica, além de consulta a especialistas (Departamento de Botânica ESALQ/USP). Algumas plantas não foram identificadas por falta de material botânico adequado, no período de desenvolvimento do projeto. Após a identificação das espécies, elas foram separadas em três grupos, quanto à procedência: 1 - plantas nativas, originárias do território brasileiro; 2 - plantas exóticas, não-originárias do território brasileiro e 3 - plantas não-identificadas.

Quanto à conformação geral da árvore, utilizaramse os parâmetros: 1- aspecto normal, quando a maioria das características foi mantida; 2 - aspecto anormal, quando houve descaracterização do indivíduo por podas malfeitas, drásticas ou ausência de podas de condução. 
Quanto à ocorrência de podas, elas foram separadas em dois tipos: 1 - limpeza e condução, quando foi realizada para a retirada de ramos secos, doentes ou malformados, sem alterar a estrutura típica da espécie; 2 drástica, quando realizada para a retirada de ramos grossos, alterando a estrutura da espécie.

A altura das plantas foi medida com a utilizaçãoda prancheta dendrométrica. Para o diâmetro de copa, utilizouse trena de $30 \mathrm{~m}$ e foram consideradas duas medidas, uma no sentido norte/sul e outra no sentido leste/oeste, verificando-se a uniformidade da copa quanto ao seu desenvolvimento e o índice de cobertura arbórea.

A literatura específica (MILANO \& DALCIN, 2000) recomenda que a primeira ramificação ocorra acima de dois metros do solo, porém, como grande parte das árvores se encontrava fora da área de circulação de pedestres, esse dado não apresentou grande relevância.

A partir da análise visual, os aspectos físicos da raiz, tronco e copa foram divididos em três categorias: saudável - isento de sinais de pragas, doenças ou injúrias mecânicas, com forma característica da espécie; recuperável - com sinais de pragas, doenças ou injúrias mecânicas, mas que podem ser tratadas; irrecuperável - com alto índice de pragas, doenças ou injúrias mecânicas; as plantas com um dos itens (raiz, tronco ou copa) nessas condições devem ser suprimidas.

\section{RESULTADOS E DISCUSSÃO}

No levantamento da vegetação arbórea existente nas praças do município de Vinhedo (SP), foram encontradas 764 indivíduos com CAP acima de dez centímetros, pertencentes a 23 famílias botânicas, divididas em 53 espécies. Outros 32 indivíduos não foram identificados.

A tabela 2 relaciona as espécies encontradas e sua abundância relativa (expressa em percentagem) em todas as praças de Vinhedo (SP).

A espécie de maior abundância relativa foi Syagrus romanzoffiana (jerivá) com 31,94\%, não ocorrendo apenas nos bairros B6 e B7, seguida por Pinus sp (pinus) com $11,65 \%$. O restante das espécies não ultrapassou $7 \%$ de ocorrência, valor este que, segundo GREY \& DENEKE (1978), está de acordo com a percentagem máxima recomendada de 10 a 15 \% por espécie da composição total.

MOTTA(1998), em Belo Horizonte (MG), também encontrou uma grande diversidade, no seu caso, nenhuma espécie contribuiu com mais de 6\%. Resultado semelhante foi observado por RODRIGUES et al. (1994), em Brasília (DF), que não encontraram nenhuma espécie com freqüência superior a $7 \%$.

A terceira espécie de maior abundância relativa foi Caesalpinia peltophoroides, (sibipiruna) aparecendo em 6,02\% das praças da cidade de Vinhedo. Essa espécie caducifólia tem sido largamente utilizada em arborização urbana, porém seus pequenos folíolos podem causar o entupimento de calhas, o que pode levar a eventuais reclamações da população, quando utilizada na arborização viária. SOUSA et al. (1990), em levantamento realizado nas árvores de rua na cidade de Botucatu (SP), observaram que $70 \%$ das árvores encontradas na parte central e antiga da cidade eram C. peltophoroides. WINTERS et al. (1992) também observaram alta percentagem de C. peltophoroides, 53,22\%, em trabalho realizado em ruas e avenidas em 295 municípios do Estado de São Paulo. O mesmo ocorreu em trabalho realizado por MILANO et al. (1992c) em Vitória (ES), em que $C$. peltophoroides fazia parte de um grupo das três espécies mais plantadas na cidade, perfazendo um total de 66,90\%. MICHI \& COUTO (1996) trabalhando no município de Piracicaba (SP) e MARTINS et al. (1992), em levantamento realizado nas ruas de Viçosa (MG), observaram que $17,90 \%$ e $10,65 \%$, respectivamente, das árvores inventariadas eram C. peltophoroides.

O Ligustrum japonicum, outra espécie de destaque, ocorreu em 5,37\% das praças de Vinhedo (SP). Em Viçosa (MG) 34,07\% das árvores inventariadas pertenciam a essa espécie (MARTINS et al., 1992). O mesmo gênero predomina na arborização urbana de Santa Maria (RS) com 20,38\% (SANTOS \& TEIXEIRA, 1990), em Curitiba (PR) com 15,40\% (MILANO et al., 1992b), porém não é a mesma espécie encontrada em Vinhedo (SP).

Em nenhuma das áreas inventariadas em Vinhedo (SP) foram encontradas espécies de cerrado, cerradão e capoeiras, vegetações nativas da região, conforme recomendam TOLEDO FILHO \& PARENTE (1988) e BARBOSA et al. (2001). Porém, segundo LORENZI (1992), $S$. romanzoffiana (jerivá) ocorre em quase todas as formações vegetais, e é freqüentemente encontrada em capoeiras e áreas recém-abandonadas.

Quando se compararam os bairros, observou-se que, além da grande ocorrência de algumas espécies, estas se encontram concentradas por bairro, o que pode criar, conforme MILANO et al. (1992a), um quadro delicado do ponto de vista fitossanitário, estético e paisagístico.

Na tabela 3, estão relacionadas às espécies de maior abundância distribuídas por praça na cidade de Vinhedo (SP). As espécies arbóreas com maior abundância relativa (acima de $10 \%$ por bairro) são descritas na tabela 4.

Analisando-se a procedência das árvores levantadas por praças, observa-se na tabela 5, que na maioria das praças (63,64\%), 33,13\% das espécies são exóticas. Pode-se observar que, dos oito bairros estudados, apenas o Bairro B7 possuía quantidade maior de espécies exóticas. Esse dado, porém, não deve ser considerado, uma vez que a área é uma praça com apenas três exemplares arbóreos, correspondendo a 0,39\% do total de indivíduos.

Para a análise da conformação geral da copa dos indivíduos foram observados altura da primeira bifurcação, formato e diâmetro da copa, para verificação da manutenção das características naturais e condução apropriada de cada espécie.

A figura 1 indica a ocorrência de plantas com conformação geral normal e anormal distribuídas por bairro. Pode-se observar que, em todos os bairros, a maioria dos indivíduos tem conformação geral normal, demonstrando a prática de tratos culturais adequados.

A execução correta de podas de condução é, em grande parte, responsável pela manutenção das características naturais de cada indivíduo. Na figura 2, pode-se notar que, na maioria dos casos, as podas foram 
feitas corretamente ou não houve a necessidade de nenhuma intervenção. Poucos foram os casos em que se aplicaram podas drásticas. Segundo (MILANO \& DALCIN, 2000), sob a ótica técnica, as podas devem garantir a longevidade da arborização e corrigir e/ou minimizar os efeitos de um planejamento inadequado, respeitando-se as características de cada espécie. No caso desse estudo, uma vez que os indivíduos estavam locados em praças, não houve a necessidade de podas drásticas, porque não havia fiação elétrica, fazendo com que as plantas mantivessem grande parte da arquitetura natural dos galhos na planta.

As plantas sem podas foram, em sua maioria, palmeiras, que normalmente não aceitam intervenção dessa natureza.

TRINDADE \& ROCHA (1990) verificaram que em apenas 6,29\% dos indivíduos analisados, em praças, na cidade de Curitiba (PR), foram feitas podas drásticas. MARTINS et al. (1992) observaram que 34,58\% das árvores inventariadas em Viçosa (MG) tiveram podas de limpeza (condução) e 23,71\%, poda total (drástica). MILANO et al. (1992c) constataram que em 42,30\% das árvores de ruas de Vitória (ES) sofreram podas que causaram mutilações diversas (poda drástica) e favoreceram apenas à fiação. ANDRADE (2002), em levantamento realizado na arborização viária da cidade de Campos do Jordão (SP), observou que em $59,30 \%$ das árvores foram realizadas podas drásticas e em $81,80 \%$, poda de condução, e apenas $18,20 \%$ não foram podadas.

Pode-se concluir que a ocorrência de podas adequadas nos indivíduos analisados deve-se, também ao fato de não se localizarem sob fiação elétrica.

Em relação à altura de primeira bifurcação, verificou-se grande proporção de árvores com primeira ramificação abaixo de dois metros, conforme se observa na figura 3 , porém essas plantas se encontram, na maioria dos casos, fora da área de circulação, portanto sem causar problemas aos pedestres ou veículos.

Em Vinhedo, 50,15\% das árvores inventariadas estavam saudáveis, 42,54\% eram recuperáveis e 7,33\% eram irrecuperáveis. COSTA \& HIGUCHI (1999), em levantamento realizado na arborização de ruas de Manaus (AM), observaram que $10 \%$ das árvores estavam boas (saudáveis), 74\% regulares (recuperáveis) e 16\% ruins (irrecuperáveis). MILANO et al. (1992b) encontraram 39,4\% de árvores em bom estado fitossanitário, 54,4\% de árvores em estado satisfatório, 5\% ruins, e 1,2\% de árvores mortas ou em estado irrecuperável em Curitiba (PR). SANTOS et al. (1991), em trabalho realizado em Bento Gonçalves (RS), encontraram 64,80\% das árvores das ruas do centro saudáveis; 21,49\% recuperáveis e 13,71\% irrecuperáveis.

Os resultados foram distribuídos por bairros e praças, conforme demonstrado na tabela 6. As plantas classificadas como "saudáveis" só necessitam de cuidados de manutenção, enquanto a classe "recuperável” indica a necessidade de intervenções direcionadas, tais como: podas de condução e tratamento fitossanitário e as “irrecuperáveis” deverão ser substituídas. Pode-se observar que apenas o Bairro B8 teve alta percentagem de árvores irrecuperáveis $(35,48 \%)$, porém esse fato é explicável, por se tratar de exemplares que foram mantidos após a implantação da Praça B8P1, sendo que nesses indivíduos ocorreram altos índices de pragas, doenças ou injúrias mecânicas.

A praça B5P1 obteve a maior percentagem de árvores saudáveis (82,26\%), indicando que foram utilizadas técnicas adequadas de manejo. A praça B1P2 concentrou a maior quantidade de árvores recuperáveis (87,50\%), o que mostrou a necessidade de melhoria das técnicas utilizadas de manejo, e a praça B8P1, a maior percentagem de árvores irrecuperáveis (35,48\%), o que foi justificado pela presença de árvores já existentes e mantidas na implantação da praça, porém sem a forma de condução adequada.

\section{REFERÊNCIAS}

ANDRADE, T.O. Inventário e análise da arborização viária da estância turística de Campos do Jordão, SP. Escola Superior de Agricultura “Luiz de Queiroz”,. Dissertação (Mestrado em Fitotecnia), Piracicaba. 2002. 112 p.

BARBOSA, L.M.; MARTINS, S.E.; MATIOLLI, D.S. \& BARBOSA, K.C. Conceitos e sugestões para conservação da diversidade biológica em áreas urbanas. Caderno UniABC Ciências Biológicas, São Paulo, v.3, n.7, p. 44-62, 2001.

COSTA, L.A. da \& HIGUCHI, N. Arborização de ruas de Manaus: avaliação qualitativa e quantitativa. Revista Árvore, Viçosa, v.23, n.2, p.223-232, 1999.

GREY, G.W. \& DENEKE, F.J. Urban forestry. New York: John Wiley, 1978. 279 p.

LORENZI, H. Árvores brasileiras: manual de identificação e cultivo de plantas arbóreas nativas do Brasil. Nova Odessa: Editora Plantarum, 1992. 352 p.

LORENZI, H. Árvores brasileiras: manual de identificação e cultivo de plantas arbóreas nativas do Brasil. 2.ed. Nova Odessa: Editora Plantarum, 1998. 352 p.

MARTINS, S.V.; PAIVA, H.N. de; SOARES, C.P.B. \& JACOVINE, L.A.G. Avaliação quali-quantitativa da arborização de ruas de Viçosa-MG. In: CONGRESSO BRASILEIROSOBREARBORIZAÇÃOURBANA, 1., 1992, Vitória. Anais... Vitória, 1992. p.317-326.

MICHI, S.M.P. \& COUTO, H.T.Z. do. Estudo de dois métodos de amostragem de árvores de rua na cidade de Piracicaba, SP. In: CONGRESSO BRASILEIRO DE ARBORIZAÇÃO URBANA, 3., 1996, Salvador. Anais... Salvador, 1996. p.89-96.

MILANO, M.S.; SARNOWSKI FILHO, O.; ROBAYO, J.A.M. Estudo comparativo de unidades amostrais utilizadas para inventário quali-quantitativo de arborização de ruas em Curitiba. In: CONGRESSOBRASILEIROSOBRE ARBORIZAÇÃO URBANA, 1, 1992a, Vitória. Anais... Vitória, 1992a, p.343-350.

MILANO, M.S.; NUNES, M. L.; SANTOS L.A. dos; SARNOWSKI FILHO, O.; ROBAYO, J.A.M. Aspectos quali-quantitativos da arborização de ruas de Curitiba (1991). In: CONGRESSO BRASILEIRO SOBRE 
ARBORIZAÇÃO URBANA, 1., 1992b, Vitória. Anais... Vitória, 1992b, p.199-210..

MILANO, M.S.; WANDEMBRUCK, A.; DALLA, A.C.; SIQUEIRA, E.S.; KALIL,F.A., ZECCHINELLI, I.S.; GATTI, M.; MORES, M.; LINHARES, M.A.; HORTA, M.M.M.; SANT’ANNA, A.L.V.; BRITO, F.A.N.; SIMÕES,J.M.; SADETTI, M.; CEBIN, R.; CONEGIAN, S.J.G.; PEREIRA, S.V.; RESENDE, S.A. Situação da arborização de Vitória ES. In: CONGRESSO BRASILEIRO SOBRE ARBORIZAÇÃO URBANA, 1., 1992c, Vitória. Anais... Vitória, 1992c, p.147-159..

MILANO, M.; DALCIN, E. Arborização de vias públicas. Rio de Janeiro: Light, 2000. 226 p.

MOTTA, G.L.O. Inventário da arborização de áreas, utilizando um sistema hierárquico para endereço impreciso. 1998. 124 p. Dissertação (Mestrado) Universidade Federal de Viçosa,, Viçosa.

OLIVEIRA, J.B. de; CAMARGO, M.N.; ROSSI, M. \& CALDERANO FILHO, B. Mapa pedológico do Estado de São Paulo: legenda expandida. Campinas: Instituto Agronômico de Campinas, Rio de Janeiro: Embrapa Solos, 64p. Escala 1:100.000. 1999.

RODRIGUES, M.G.R.; BREDT,A. \& UIEDA, W. Arborização de Brasília, Distrito Federal, e possíveis fontes para morcegos fitófagos. In: CONGRESSO BRASILEIRO DE ARBORIZAÇÃO URBANA, 2., 1994, São Luís,. Anais... São Luís: Sociedade Brasileira de Arborização Urbana, 1994. p.331-326.

SANTOS, N.R.Z. dos \& TEIXEIRA I.F. Levantamento quantitativo e qualitativo da arborização do bairro centro da cidade de Santa Maria, RS. In: ENCONTRO NACIONAL SOBRE ARBORIZAÇÃO URBANA, 3., 1990, Curitiba. Anais... Curitiba: FUPEF do Paraná, 1990. p. 263-275.

SANTOS, N.R.Z. dos \& TEIXEIRA, I.F. Avaliação plástica da vegetação das praças de Veranópolis (RS). In: ENCONTRO NACIONAL SOBRE ARBORIZAÇÃO URBANA, 6., 2001, Brasília. Anais... Brasília: s.ed., 2001. (compact disc).

SANTOS, N.R.Z. dos; TEIXEIRA I.F. \& VACARRO, S. Avaliação qualitativa da arborização da cidade de Bento Gonçalves, RS. Ciência Florestal, v.1, n.1, p 88-99, 1991.
SOUSA, M.A.L.B.; CONTE, A.M.; BARDELLI, G. \& LATINI, M. Análise e caracterização da arborização viária da parte central da cidade de Botucatu - SP. In: ENCONTRO NACIONAL SOBREARBORIZAÇÃO URBANA, 3., 1990, Curitiba.. Anais... Curitiba: FUPEF do Paraná, 1990. p.236243.

TOLEDO FILHO, D.V. de \& PARENTE, P.R. Arborização urbana com essências nativas. São Paulo: Instituto Florestal, 1988. 19-31p. (IF. Boletim Técnico, 42).

TRINDADE, A.V.C. \& ROCHA, M.P. Avaliação da situação fitossanitária das árvores de praças em Curitiba. In: ENCONTRO NACIONAL SOBRE ARBORIZAÇÃO URBANA, 3., 1990, Curitiba.. Anais... Curitiba: FUPEF, 1990. p.324-30.

VELOSO, H.P.; RANGEL FILHO; A.L.R. \& LIMA, J.C.A. Classificação da vegetação brasileira, adaptada a um sistema universal. Rio de Janeiro: IBGE, Departamento de Recursos Naturais e Estudos Ambientais, 1991,124p..

VERAS, L.M.S.C. . Plano de arborização de cidades metodologia. In: CONGRESSO NORDESTINO DE ECOLOGIA, 1., 1986, Recife. Anais... Recife: UFRPE, Departamento de Biologia, 1986. p..8-14.

VINHEDO. Prefeitura Municipal. Secretaria do Comércio, Indústria e Turismo. Histórico do Município de Vinhedo. Vinhedo, 2000. 15p.

WINTERS, G.H.M.; PERRENOUD, L.A.S. \& MOHAMED, E.M.H.M. A arborização urbana em 295 municípios de São Paulo. In: CONGRESSO BRASILEIRO SOBRE ARBORIZAÇÃOURBANA, 1., 1992, Vitória .Anais... Vitória: Prefeitura, 1992, p. 175-192. 
Tabela 1. Codificação e denominação dos bairros e praças existentes na cidade de Vinhedo (SP) 2002

\begin{tabular}{|c|c|c|c|}
\hline \multicolumn{2}{|c|}{ BAIRRO } & \multicolumn{2}{|r|}{ PRAÇA } \\
\hline Código & Nome & Código & Nome \\
\hline B1 & João XXIII & $\begin{array}{l}\text { B1P1 } \\
\text { B1P2 } \\
\text { B1P3 } \\
\text { B1P4 } \\
\text { B1P5 }\end{array}$ & $\begin{array}{l}\text { Uderico Reichel * } \\
\text { Padre Luiz Sais } \\
\text { sem nome } \\
\text { Vila João XXIII } \\
\text { Uderico Reichel* }\end{array}$ \\
\hline B2 & Aquário & $\begin{array}{l}\mathrm{B} 2 \mathrm{P} 1 \\
\mathrm{~B} 2 \mathrm{P} 2\end{array}$ & $\begin{array}{l}\text { Aquário } \\
\text { sem nome }\end{array}$ \\
\hline B3 & Santa Rosa & $\begin{array}{l}\text { B3P1 } \\
\text { B3P2 }\end{array}$ & $\begin{array}{l}\text { Dom Martinho Albert Roth } \\
\text { Da Vitória }\end{array}$ \\
\hline B4 & Vila Planalto & $\begin{array}{l}\text { B4P1 } \\
\text { B4P2 }\end{array}$ & $\begin{array}{l}\text { Biquinha } \\
\text { Comendador Paulo Storani, }\end{array}$ \\
\hline B5 & Centro & $\begin{array}{l}\text { B5P1 } \\
\text { B5P2 } \\
\text { B5P3 } \\
\text { B5P4 } \\
\text { B5P5 }\end{array}$ & $\begin{array}{l}\text { De Sant'Ana } \\
\text { Centro de Convivência } \\
\text { Corazzari } \\
\text { sem nome } \\
\text { sem nome }\end{array}$ \\
\hline B6 & Jardim Três Irmãos & $\begin{array}{l}\mathrm{B} 6 \mathrm{P} 1 \\
\mathrm{~B} 6 \mathrm{P} 2 \\
\mathrm{~B} 6 \mathrm{P} 3 \\
\mathrm{~B} 6 \mathrm{P} 4\end{array}$ & $\begin{array}{l}\text { Prefeito Jair Mendes de Barros } \\
\text { sem nome } \\
\text { sem nome } \\
\text { sem nome }\end{array}$ \\
\hline B7 & Jardim Von Zuben & B7P1 & sem nome \\
\hline B8 & Capela & B8P1 & Centro de Lazer do Trabalhador "Aurora Sudário" \\
\hline
\end{tabular}

* A praça Uderico Reichel inicialmente era grande, foi dividida e atualmente parte dela pertence a praça B1P1 e a B1P5.

Tabela 2. Espécies inventariadas em todas as praças de Vinhedo (SP), abundância relativa de indivíduos (expressa em percentagem), no ano 2002

\begin{tabular}{llcc}
\hline Nome comum & Nome científico & Quantidade & $\begin{array}{c}\text { Porcentagem } \\
(\%)\end{array}$ \\
\hline Abacateiro & Persea americana Mill. & 0,39 \\
Aceroleira & Malpighia glabra L. & 3 & 0,13 \\
Açoita cavalo & Luehea divaricata Mart. & 1 & 0,13 \\
Amoreira & Morus nigra L. & 1 & 0,39 \\
Aroeira-pimenteira & Schinus terebinthifolius Raddi & 3 & 1,83 \\
Aroeira-salsa & Schinus molle L. & 14 & 0,39 \\
Canela & Nectrandra rigida (Kunth.) Nees & 3 & 0,13 \\
Cereja do Rio Grande & Eugenia involucrata DC. & 1 & 0,13 \\
Cerejinha & Ficus microcarpa L. & 1 & 0,13 \\
Cinamomo & Melia azedarach L. & 1 & 1,05 \\
Cipreste italiano & Cupressus sempervirens Lam. & 8 & 0,13 \\
Coração de negro & Poecilanthe parviflora Benth. & 1 & 0,39 \\
Eritrina & Erythrina speciosa Andr. & 3 & 0,13 \\
Espatódea & Spathodea campanulata Beauv. & 1 & 4,71 \\
Eucalipto & Eucalyptus sp. & 36 & 0,26 \\
Falsa murta & Murraya exotica L. & 2 & 0,13 \\
Fênix & Phoenix roebelenii O' Brien & 1 & 0,26 \\
Figueira & Ficus sp. & 2 & 0,13 \\
\hline & & 1 & \\
\hline
\end{tabular}


Tabela 2. continuação

\begin{tabular}{|c|c|c|c|}
\hline Nome comum & Nome científico & Quantidade & $\begin{array}{l}\text { Porcentagem } \\
(\%)\end{array}$ \\
\hline Figueira benjamina & Ficus benjamina $\mathrm{L}$. & 14 & 1,83 \\
\hline Figueira branca & Ficus pohliana Miq. & 5 & 0,65 \\
\hline Flamboyant & Delonix regia (Boj. Ex Hook.) Raf. & 6 & 0,79 \\
\hline Goiabeira & Psidium guajava $\mathrm{L}$. & 2 & 0,26 \\
\hline Grevília & Grevillea robusta A. Cunn. & 2 & 0,26 \\
\hline Guaraná paulista & Piscidia erythrina $\mathrm{L}$. & 1 & 0,13 \\
\hline Ipê amarelo & $\begin{array}{l}\text { Tabebuia chrysotricha (Mart. ex DC.) } \\
\text { Standl. }\end{array}$ & 45 & 5,89 \\
\hline Ipê de jardim & Stenolobium stans (L.) H. B. \& K. & 1 & 0,13 \\
\hline Ipê roxo & Tabebuia impetiginosa (Mart.) Standl. & 2 & 0,26 \\
\hline Jabuticabeira & Myrciaria cauliflora Berg. & 5 & 0,65 \\
\hline Jacarandá mimoso & Jacaranda mimosaefolia D .Don & 5 & 0,65 \\
\hline Jambolão & Eugenia jambolana Sam. & 1 & 0,13 \\
\hline Jenipapo & Genipa americana $\mathrm{L}$. & 1 & 0,13 \\
\hline Jerivá & Syagrus romanzoffiana (Cham.) Glassm. & 244 & 31,94 \\
\hline Ligustro & Ligustrum japonicum Thumb. & 41 & 5,37 \\
\hline Limoeiro & Citrus aurantifolia Swing. & 1 & 0,13 \\
\hline Mangueira & Mangifera indica $\mathrm{L}$. & 6 & 0,79 \\
\hline Munguba & Pachira aquatica Aubl. & 2 & 0,26 \\
\hline Não identificado & Não identificado & 32 & 4,19 \\
\hline Paineira & Chorisia speciosa A. St-Hil. & 16 & 2,09 \\
\hline Palmeira cariota & Caryota urens L. & 1 & 0,13 \\
\hline Palmeira leque & Livistona chinensis (Jacq.) R.Br. & 1 & 0,13 \\
\hline Palmeira seafortia & $\begin{array}{l}\text { Archontophoenix cunninghamiana } \\
\text { H.Wendl. \& Drude }\end{array}$ & 22 & 2,88 \\
\hline Palmeira triangular & Dypsis decaryi (Jum.) Beentje \& J.Dransf. & 16 & 2,09 \\
\hline Pata de vaca & Bauhinia variegata $\mathrm{L}$. & 9 & 1,18 \\
\hline Pata de vaca branca & Bauhinia variegata L. var. candida & 1 & 0,13 \\
\hline Pau-brasil & Caesalpinia echinata Lam. & 9 & 1,18 \\
\hline Pau ferro & $\begin{array}{l}\text { Caesalpinia ferrea Mart. ex Tul.var. } \\
\text { leiostachya Benth. }\end{array}$ & 8 & 1,05 \\
\hline Peroba branca & $\begin{array}{l}\text { Chrysophyllum gonocarpum (Mart. \& } \\
\text { Eichl.) Engl. }\end{array}$ & 1 & 0,13 \\
\hline Pinus & Pinus sp. & 89 & 11,65 \\
\hline Pitangueira & Eugenia uniflora $\mathrm{L}$. & 2 & 0,26 \\
\hline Quaresmeira & Tibouchina granulosa Cogn. & 17 & 2,23 \\
\hline Resedá & Lagerstroemia indica $\mathrm{L}$. & 1 & 0,13 \\
\hline Romã & Punica granatum $\mathrm{L}$. & 1 & 0,13 \\
\hline Sete copas & Terminalia catappa $\mathrm{L}$. & 2 & 0,26 \\
\hline Sibipiruna & Caesalpinia peltophoroides Benth. & 46 & 6,02 \\
\hline Tipuana & Tipuana tipu (Benth.) O. Kuntze & 23 & 3,01 \\
\hline
\end{tabular}


Tabela 3. Espécies de maior abundância expressa em percentagem, observadas nas praças de Vinhedo (SP), 2002

\begin{tabular}{|c|c|c|c|}
\hline Praça & Nome científico & Nome comum & Percentagem $(\%)$ \\
\hline B1P1 & Caesalpinia peltophoroides Benth. & Sibipiruna & 54,55 \\
\hline B1P2 & Caesalpinia peltophoroides Benth. & Sibipiruna & 62,50 \\
\hline B1P3 & Caesalpinia peltophoroides Benth. & Sibipiruna & 61,54 \\
\hline B1P4 & Caesalpinia peltophoroides Benth. & Sibipiruna & 27,27 \\
\hline B1P5 & Tipuana tipu (Benth.) O. Kuntze & Tipuana & 42,86 \\
\hline $\mathrm{B} 2 \mathrm{P} 1$ & Syagrus romanzoffiana (Cham.) Glassm. & Jerivá & 67,03 \\
\hline $\mathrm{B} 2 \mathrm{P} 2$ & Tipuana tipu (Benth.) O. Kuntze & Tipuana & 46,67 \\
\hline B3P1 & Caesalpinia peltophoroides Benth. & Sibipiruna & 29,41 \\
\hline B3P2 & Syagrus romanzoffiana (Cham.) Glassm. & Jerivá & 68,75 \\
\hline B4P1 & Syagrus romanzoffiana (Cham.) Glassm. & Jerivá & 66,67 \\
\hline \multirow[t]{2}{*}{ B4P2 } & Syagrus romanzoffiana (Cham.) Glassm. & Jerivá & 36,36 \\
\hline & Ligustrum japonicum Thumb. & Ligustro & 36,36 \\
\hline B5P1 & Syagrus romanzoffiana (Cham.) Glassm. & Jerivá & 48,39 \\
\hline B5P2 & Pinus sp. & Pinus & 30,42 \\
\hline B5P3 & Syagrus romanzoffiana (Cham.) Glassm. & Jerivá & 40,00 \\
\hline \multirow[t]{2}{*}{ B5P4 } & Tabebuia chrysotricha (Mart. ex DC.) Standl. & Ipê amarelo & 38,46 \\
\hline & Caesalpinia peltophoroides Benth. & Sibipiruna & 38,46 \\
\hline B5P5* & -- & -- & 0,00 \\
\hline B6P1 & Caesalpinia ferrea Mart. Ex Tul.var. leiostachya Benth. & Pau-ferro & 21,74 \\
\hline B6P2 & Ligustrum japonicum Thumb. & Ligustro & 87,50 \\
\hline B6P3* & - & -- & 0,00 \\
\hline B6P4* & -- & -- & 0,00 \\
\hline B7P1 & Ficus benjamina $\mathrm{L}$. & Figueira bejamina & 66,67 \\
\hline B8P1 & Ligustrum japonicum Thumb. & Ligustro & 25,81 \\
\hline
\end{tabular}


Tabela 4. Espécies arbóreas com abundância relativa acima de 10\%, presentes nos diferentes bairros da cidade de Vinhedo (SP), 2002

\begin{tabular}{llcc}
\hline Bairro & Nome científico & Quantidade & Freqüência (\%) \\
\hline B1 & Caesalpinia peltophoroides Benth. & 28 & 38,89 \\
B2 & Syagrus romanzoffiana (Cham.) Glassm. & 123 & 62,76 \\
B3 & Caesalpinia peltophoroides Benth. & 10 & 20,00 \\
& Ligustrum japonicum Thumb. & 8 & 16,00 \\
& Syagrus romanzoffiana $($ Cham.) Glassm. & 13 & 26,00 \\
& Ligustrum japonicum Thumb. & & \\
B4 & Syagrus romanzoffiana (Cham.) Glassm. & 12 & 26,67 \\
& Syagrus romanzoffiana (Cham.) Glassm. & 20 & 44,44 \\
B5 & Caesalpinia ferrea Mart. Ex Tul.var. leiostachya & 84 & 25,07 \\
B6 & Benth. & 5 & 15,63 \\
& Ligustrum japonicum Thumb. & 7 & 21,88 \\
& Ficus benjamina L. & & 66,67 \\
B7 & Schinus molle Linn. & 2 & 33,33 \\
& Ligustrum japonicum Thumb. & 1 & 25,81 \\
B8 & Myrciaria cauliflora Berg. & 8 & 16,13 \\
& Schinus terebinthifolius Raddi & 5 & 19,35 \\
& & 6 &
\end{tabular}

Tabela 5. Abundância relativa, em percentagem, das espécies, por bairros e praças, classificadas em nativas, exóticas e não-identificadas, na cidade de Vinhedo (SP), 2002

\begin{tabular}{|c|c|c|c|c|}
\hline \multirow{2}{*}{ Bairro } & \multirow{2}{*}{ Praças } & \multicolumn{3}{|c|}{ Procedência (\%) } \\
\hline & & Nativa & Exótica & Não-identificada \\
\hline B1 & & 54,17 & 41,67 & 4,17 \\
\hline B2 & & 72,96 & 24,49 & 2,55 \\
\hline B3 & & 58,00 & 34,00 & 8,00 \\
\hline B4 & & 48,89 & 40,00 & 11,11 \\
\hline B5 & & 49,85 & 42,69 & 7,46 \\
\hline B6 & & 28,13 & 28,13 & 43,75 \\
\hline B7 & & 3,13 & 66,67 & 30,21 \\
\hline B8 & & 67,74 & 32,26 & 0,00 \\
\hline & B1P1 & 54,55 & 45,45 & 0,00 \\
\hline & $\mathrm{B} 1 \mathrm{P} 2$ & 62,50 & 37,50 & 0,00 \\
\hline & B1P3 & 61,54 & 38,46 & 0,00 \\
\hline & B1P4 & 57,58 & 33,33 & 9,09 \\
\hline & B1P5 & 14,29 & 85,71 & 0,00 \\
\hline & $\mathrm{B} 2 \mathrm{P} 1$ & 77,35 & 19,89 & 2,76 \\
\hline & $\mathrm{B} 2 \mathrm{P} 2$ & 20,00 & 80,00 & 0,00 \\
\hline
\end{tabular}


Tabela 5. continuação

\begin{tabular}{|c|c|c|c|c|}
\hline \multirow{2}{*}{ Bairro } & \multirow{2}{*}{ Praças } & \multicolumn{3}{|c|}{ Procedência (\%) } \\
\hline & & Nativa & Exótica & Não-identificada \\
\hline & B3P1 & 41,18 & 47,06 & 11,76 \\
\hline & B3P2 & 93,75 & 6,25 & 0,00 \\
\hline & B4P1 & 75,00 & 16,67 & 8,33 \\
\hline & B4P2 & 39,39 & 48,48 & 12,12 \\
\hline & B5P1 & 56,45 & 38,48 & 8,06 \\
\hline & B5P2 & 45,42 & 46,67 & 7,92 \\
\hline & B5P3 & 50,00 & 45,00 & 5,00 \\
\hline & B5P4 & 100,00 & 0,00 & 0,00 \\
\hline & B5P5 & 0,00 & 0,00 & 0,00 \\
\hline & B6P1 & 37,50 & 8,33 & 54,17 \\
\hline & B6P2 & 0,00 & 87,50 & 12,50 \\
\hline & B6P3 & 0,00 & 0,00 & 0,00 \\
\hline & B6P4 & 0,00 & 0,00 & 0,00 \\
\hline & B7P1 & 33,33 & 66,67 & 0,00 \\
\hline & B8P1 & 67,74 & 32,26 & 0,00 \\
\hline
\end{tabular}

Tabela 6. Grau de sanidade (expresso em percentagem) das árvores, classificado como saudável, recuperável e irrecuperável, nos bairros e praças da cidade de Vinhedo (SP), 2002

\begin{tabular}{ccccc}
\hline \multirow{2}{*}{ Bairro } & Praça & & Grau de Sanidade (\%) & \\
\cline { 3 - 4 } & & Saudável & Recuperável & Irrecuperável \\
\hline B1 & 29,17 & 62,50 & 8,33 \\
B2 & 58,67 & 39,80 & 1,53 \\
B3 & & 30,00 & 68,00 & 2,00 \\
B4 & & 51,11 & 48,89 & 0,00 \\
B5 & & 54,93 & 35,22 & 9,85 \\
B6 & & 40,63 & 53,12 & 6,25 \\
B7 & & 66,67 & 33,33 & 0,00 \\
B8 & & 32,26 & 32,26 & 35,48 \\
& B1P1 & 45,45 & 36,36 & 18,18 \\
& B1P2 & 12,50 & 87,50 & 0,00 \\
& B1P3 & 30,77 & 53,85 & 15,38 \\
& B1P4 & 33,33 & 63,64 & 3,03 \\
& B1P5 & 0,00 & 85,71 & 14,29 \\
& B2P1 & 62,98 & 36,46 & 0,55 \\
\hline
\end{tabular}


Tabela 6. continuação

\begin{tabular}{ccccc}
\hline \multirow{2}{*}{ Bairro } & & Grau de Sanidade (\%) & \\
\hline & Praça & Saudável & Recuperável & Irrecuperável \\
\cline { 2 - 4 } B2P2 & 6,67 & 80,00 & 13,33 \\
B3P1 & 14,71 & 82,35 & 2,94 \\
B3P2 & 62,50 & 37,50 & 0,00 \\
B4P1 & 75,00 & 25,00 & 0,00 \\
B4P2 & 42,42 & 57,58 & 0,00 \\
B5P1 & 82,26 & 17,74 & 0,00 \\
B5P2 & 46,25 & 40,83 & 12,92 \\
B5P3 & 70,00 & 20,00 & 10,00 \\
B5P4 & 61,54 & 38,46 & 0,00 \\
B5P5 & 0,00 & 0,00 & 0,00 \\
B6P1 & 41,67 & 50,00 & 8,33 \\
B6P2 & 37,50 & 62,50 & 0,00 \\
B6P3 & 0,00 & 0,00 & 0,00 \\
B6P4 & 0,00 & 0,00 & 0,00 \\
B7P1 & 66,67 & 33,33 & 0,00 \\
B8P1 & 32,26 & 32,26 & 35,48 \\
\hline
\end{tabular}

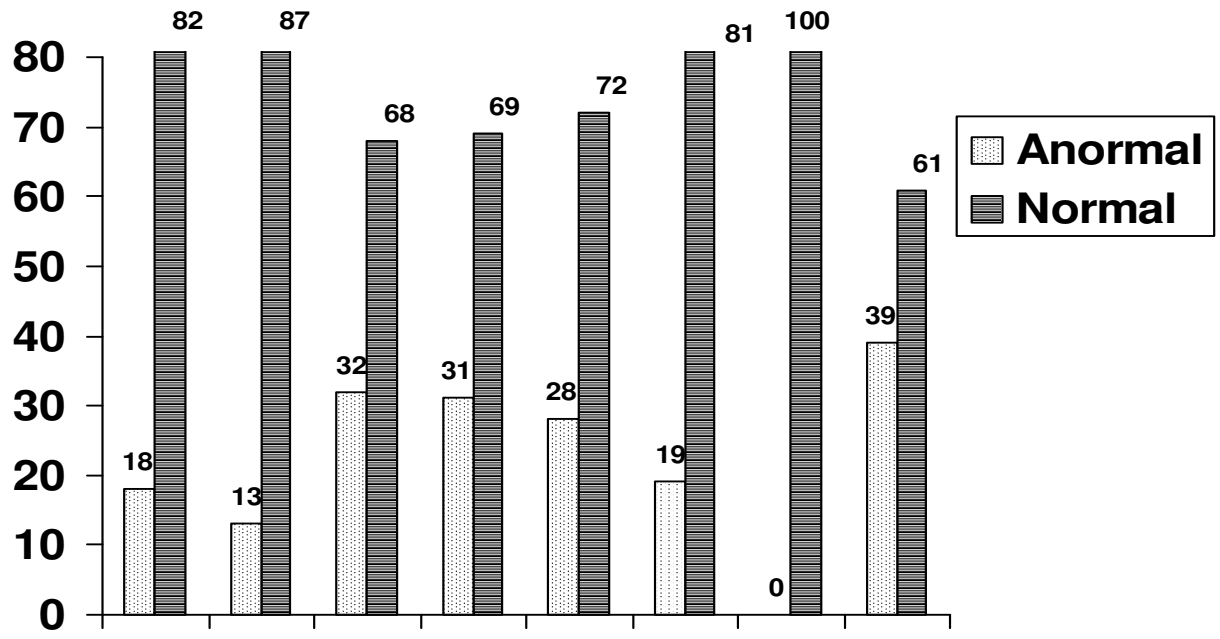

B1 $\begin{array}{lllllll}\text { B2 } & \text { B3 } & \text { B4 } & \text { B5 } & \text { B6 } & \text { B7 } & \text { B8 }\end{array}$

Figura 1. Conformação geral das árvores, expressa em percentagem, nas praças existentes nos bairros inventariados da cidade de Vinhedo (SP), 2002. 


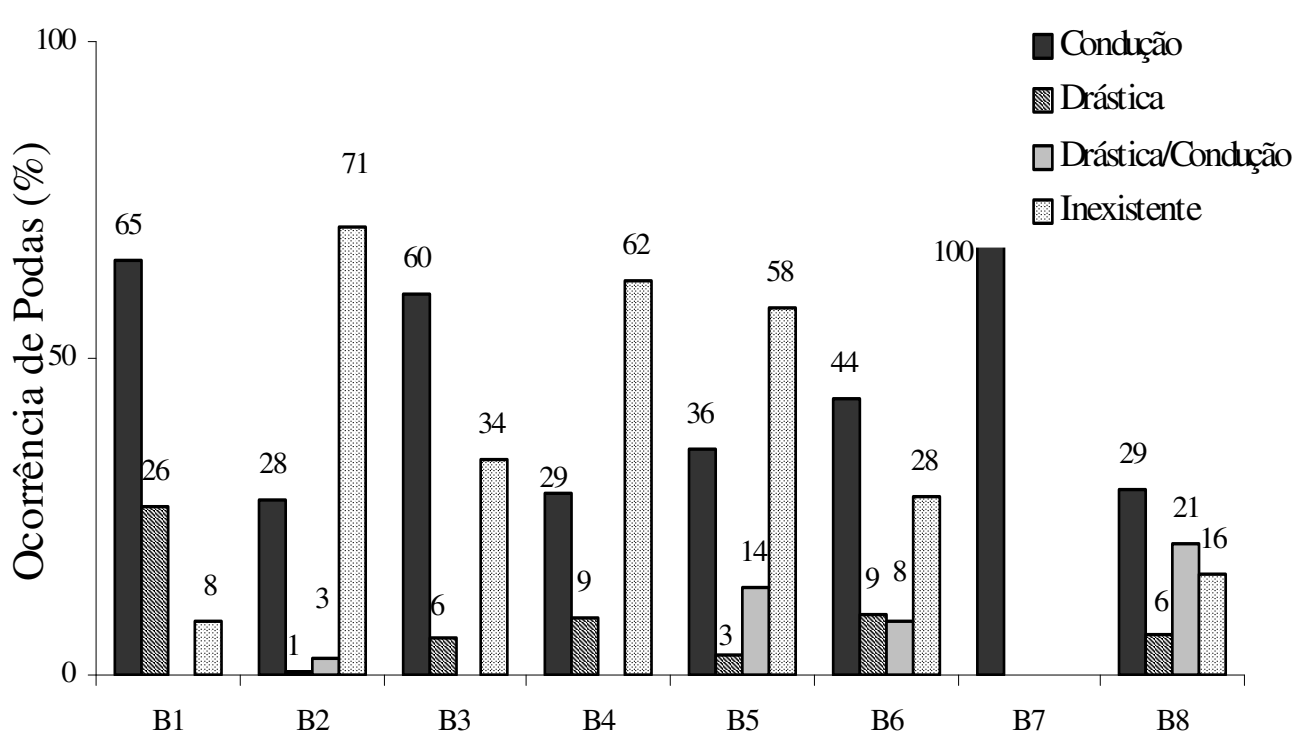

Figura 2. Tipos de podas executadas nas árvores dos diferentes bairros (B1a B8) das praças da cidade de Vinhedo (SP), 2002.

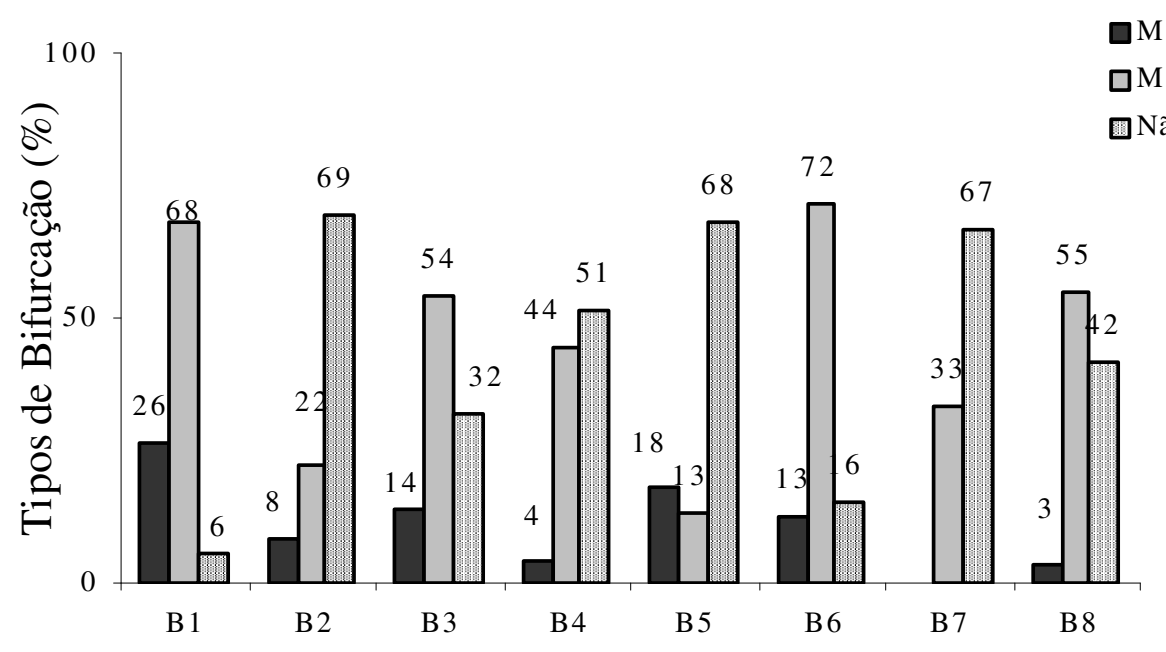

Figura 3. Altura da primeira bifurcação observada em árvores existentes nas praças dos diferentes bairros (B1 a B8) da cidade de Vinhedo (SP), 2002. 